\title{
ANALISIS KARAKTERISTIK BAHAN LENGAN RCWS (REMOTE CONTROL WEAPON SYSTEM) PADA ROBOT TEMPUR KOTA TERHADA SUDUT PENEMBAKAN
}

\author{
Latif Nur Khasan $^{1}$, Mardjuki ${ }^{* *}$, Dedy Pradigdo ${ }^{1}$ \\ ${ }^{1}$ Jurusan Teknik Otoranpur, Poltekad \\ ${ }^{2}$ Jurusan Teknik Mesin, Fakultas Teknik, Universitas Merdeka Malang \\ *Email corresponding author: mardjuki@unmer.ac.id
}

\begin{abstract}
Abstrak
Robot tempur kota merupakan alat yang digunakan untuk pertempuran kota, senjata utama yang digunakan ialah senapan SS2 V1, senapan itu sendiri ditopang dan digerakan oleh lengan yang terbagi 2 yaitu lengan 1 dan lengan 2 mampu bergerak secara elevasi.Bahan lengan yang digunakan ialah alumunium paduan, bahan tersebut diharapkan mampu menahan beban dari gaya yang terjadi terutama ketika terjadi penembakan, untuk itu diperlukan suatu pengujian agar mengetahui karakteristik dari bahan lengan Rcws. Setelah dilaksnakan pengambilan data gaya terberat yang terjadi pada lengan 1 ialah $66,725 \mathrm{~N}$ pada sudut $60^{\circ}$ dan pada lengan 2 ialah 169,602 $\mathrm{N}$ pada sudut $20^{\circ}$, bahan lengan yang digunakan ialah alumunium alloy seri 5083 mempunyai kandungan alumunium(Al) 94,978\% dan unsur utama paduan magnesium sebesar 4,297\% mempunyai sifat keuletan yang baik serta nilai kekerasan sebesar $23 \mathrm{HR}_{\mathrm{B}}$, harga impak sebesar 1,396 joule $/ \mathrm{mm}^{2}$, kemudian untuk tegangan maksimal dari alumunium 5083 ialah $13,815 \mathrm{kgf} / \mathrm{mm}^{2}$ dengan tegangan titik putus $11,41 \mathrm{kgf} / \mathrm{mm}^{2}$ dan tegangan luluh sebesar $11,712 \mathrm{kgf} / \mathrm{mm}^{2}$. Pada saat uji penembakan, lengan dapat menerima beban terberat dari sudut yang ditentukan yaitu sudut $60^{\circ}$ dan sudut $20^{\circ}$, dan kekuatan baut dengan tegangan yang diijinkan $10 \mathrm{~N} / \mathrm{mm}^{2}$ masih mampu menerimategangan yang terjadi yaitu $0,587 \mathrm{~N} / \mathrm{mm}^{2}$, sehingga alumunium alloy seri 5083 cocok digunakan untuk bahan pembuatan lengan RCWS robot tempur kota.
\end{abstract}

Kata Kunci :Lengan, Alumunium, Pengujian bahan.

\begin{abstract}
City combat robot is a tool used for city battles, the main weapon used is the SS2 V1 rifle, the rifle itself is supported and moved by the arm which is divided into 2 arms 1 and arm 2 is able to move in elevation. Arm material used is aluminum alloy, The material is expected to be able to withstand the load from the force that occurs especially when shooting occurs, for that we need a test to determine the characteristics of the Rcws arm material. After taking the data, the heaviest force that occurs in arm 1 is $66.725 \mathrm{~N}$ at an angle of 600 and in arm 2 is $169.602 \mathrm{~N}$ at an angle of 200 , the arm material used is the aluminum alloy series 5083 which has an aluminum content (Al) $94.978 \%$ and the main element is magnesium alloy 4,297\% have good tenacity and hardness value of $23 \mathrm{HRB}$, impact price of 1,396 joules / mm2, then for maximum stress of aluminum 5083 is $13,815 \mathrm{kgf} / \mathrm{mm} 2$ with breaking point voltage of 11,41 kgf/ $\mathrm{mm} 2$ and yield stress of 11,712 kgf/ mm2. At the time of the firing test, the arm can accept the heaviest load from the specified angle that is the angle of $60^{\circ}$ and the angle of $20^{\circ}$, and the strength of the bolt with the allowable stress of $10 \mathrm{~N} / \mathrm{mm} 2$ is still able to accept the deviation of $0.587 \mathrm{~N} / \mathrm{mm} 2$, so that the aluminum alloy series 5083 suitable for making RCWS city robot combat arm material.
\end{abstract}

Keywords :Arms, Aluminum, Material Testing 


\section{PENDAHULUAN}

\section{Latar Belakang}

Seiring perkembanganilmu

pengetahuan yang semakin canggih dibidang teknologi, mulai berkembang berbagai alat maupun perangkat yang memudahkan manusia, salah satu karya dibidang teknologi saat ini yang berada dikehidupan sehari-hari ialah robot.Oleh sebab itu dimiliterpun sudah memulai penggunaan tenaga robot. Dalamperkembangannya dapat diterapkan untuk membuat alat atau mesin yang mempunyaikemampuan mengikuti kegiatan militer.untuk itu dibuatlah robot tempur yang diperuntukan khusus untuk pertempuran perkotaan dilengkapi dengan sebuah lengan penggerak sebagai pengatur pergerakan dan dudukan senjata.

Lengan robot merupakan komponen yang vital dari robot tempur kota,pada saat penembakan berlangsung lengan harus dapat menahan beban senjata dan recoilsenjata,selain itu penembakan akan divariasikan dengan sudut tembak yang berbeda, oleh karena itu diperlukan bahan yang sesuai agar lengan robot tetap kuat saat menerima beban yang diterima.

Pemilihan bahan sangat berpengaruh pada fungsi kerja lengan, apabila bahan tidak sesuai akan mempengaruhi fungsi kerja lengan

yaitu pada saat penembakan terjadi dapat terjadi kerusakan diakibatkan gaya dari senjata, sehingga penembakan gagal dilakukan.

Berdasarkan permasalahan di atas maka diambil Tugas Akhir yang berjudul "ANALISIS KARAKTERISTIK BAHAN LENGAN RCWS ROBOT TEMPUR KOTA TERHADAP VARIASI SUDUT PENEMBAKAN", untuk memastikan lengan tersebut kuat menopang senjata pada saat penembakan.

\section{Rumusan Masalah.}

Adapun perumusan masalah yang timbul dalam perumusan ini yaitu :

Bagaimana karakteristik dari bahan lengan robot RCWS yang divariasikan pada sudut penembakan dengan kekuatan bahan yang direncanakan?

\section{Batasan Masalah.}

Untuk memperjelas ruang lingkup permasalahan yang dibahas, maka penulis perlu adanya batasan-batasn yang tidak diuraikan dalam penelitian, antara lain :

1.Menganalisa material bahan yang digunakan pada konstruksi lengan dengan cara :

a.Uji komposisi bahan lengan.

b.Uji impak bahan lengan.

c.Uji kekerasan bahan lengan.

d.Uji tarik bahan lengan.

2.Menganalisa tiap gaya yang terjadi pada setiap pergerakan sudut lengan. 
3. Analisa kekuatan baut.

\section{Tujuan Penelitian.}

Mengacu pada permasalahan di atas, tujuan yang ingin dicapai dalam penyusunan tugas akhir ini adalah :

Mengetahui bagaimana karakteristik dari bahan lengan robot RCWS yang divariasikan pada sudut penembakan dengan kekuatan bahan yang direncanakan

\section{Manfaat Penelitian.}

Manfaat dari penelitian ini adalah sebagai berikut :

1.Agar siswa mengetahui kekuatan bahan yang digunakan untuk lengan tersebut.

2. Agar menghasilkan lengan yang kuat terhadap beban yang diterima.

3. Dapat menganalisis kekuatan lengan secarateliti.

\section{STUDI PUSTAKA}

Dalam menganalisa karakteristik bahan yang digunakan untuk lengan RCWS pada robot tempur kota dilakukan perhitungan gaya yang terjadi terhadap lengan tersebut kemudian dilakukan pemilihan bahan yang sesuai dengan keperluan lengan tersebut, setelah ditentukan bahan dari lengan diperlukan beberapa pengujian karakteristik bahan yang digunakan, nantinya bahan tersebut akan diuji kekuatannya ketika menerima beban dari beberapa sudut yang ditentukan.

\section{Gaya dan Reaksi Gaya Pada Lengan.}

Gaya adalah penyebab pergerakan atau perubahan bentuk pada suatu benda berupa tarikan atau dorongan,

$\mathrm{N} \quad=\mathrm{m} \cdot \mathrm{g}(\mathrm{N})$

(Sumber: Sears Zemansky, 1982)

Dimana:

$$
\begin{aligned}
\mathrm{N} & =\text { Gaya Normal }(\mathrm{N}) \\
\mathrm{m} & =\text { Massa }(\mathrm{kg}) \\
\mathrm{g} & =\text { Percepatan gravitasi }\left(\mathrm{m} / \mathrm{detik}^{2}\right)
\end{aligned}
$$

Arah gaya ditentukan oleh garis aksi (garis kerja),dan tujuan gaya, garis kerja ini garis lurus yang tak terbatas dan dimana gaya tersebut bekerja, membentuk sudut terhadap suatu axis (sumbu) tetap

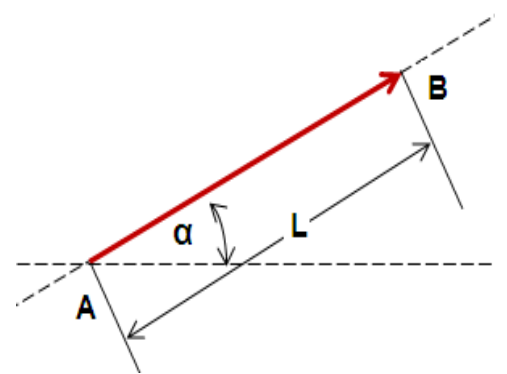

Gambar 2.1. Arah Gaya.

(Statika, TEDC Bandung, hal 3)

Keterangan :

A $\quad=$ Titik tangkap gaya.

$\mathrm{B}=$ Arah gaya

$\mathrm{AB}=$ Garis kerja gaya.

$\mathrm{L}=$ = Besar gaya.

Gaya dapat diuraikan menjadi komponen vertikal dan horizontal atau mengikuti sumbu $\mathrm{x}$ dan y, sehingga digunakan persamaan sebagai berikut: 


$$
\begin{aligned}
& F_{x}=F \cos \theta . \\
& F_{y}=F \sin \theta .
\end{aligned}
$$

(Sumber: Sears Zemansky, 1982)

\section{Analisa kekuatan baut.}

Baut adalah alat sambung dengan batang bulat dan berulir, salah satu ujungnya dibentuk kepala baut ( umumnya bentuk kepala segi enam ) dan ujung lainnya dipasang mur/pengunci.

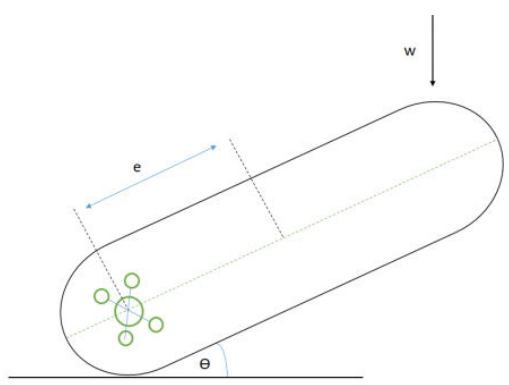

Gambar 2.4. Baut pada lengan.

1. Momen puntir pada baut $(M)$.

$$
\mathrm{M}=\mathrm{W}_{\text {Total }} \mathrm{x} \text { e }(\mathrm{Nmm})
$$

(R.S. Khurmi, Machine Design, 2005)

Dimana :

$$
\begin{array}{ll}
M & =\text { Momen baut }(\mathrm{Nmm}) \\
\mathrm{W}_{\text {Total }} & =\text { Beban total lengan }(\mathrm{N}) \\
e & =\text { Jarak pusat poros ke titik } \\
& \text { berat }(\mathrm{mm})
\end{array}
$$

2. Beban geser yang terjadi tiap-tiap baut $\left(\mathrm{W}_{\mathrm{s}}\right)$.

$$
\mathrm{W}_{\mathrm{S}}=\frac{\mathrm{W}_{\text {Total }}}{\mathrm{n}}(\mathrm{N})
$$

(R.S. Khurmi, Machine Design, 2005)
Dimana :

$$
\begin{array}{ll}
\mathrm{W}_{\mathrm{s}} & =\text { Beban geser yang terjadi } \\
& \text { pada baut }(\mathrm{N}) \\
\mathrm{W}_{\text {Total }} & =\text { Beban total lengan }(\mathrm{N}) \\
\mathrm{n} & =\text { Jumlah baut }
\end{array}
$$

3. Gaya geser maksimal pada baut (F).

$$
\mathrm{F}=\sqrt{\left(\mathrm{W}_{\mathrm{s} 1}\right)^{2}+\left(\mathrm{W}_{\mathrm{s} 2}\right)^{2}+2 \mathrm{~W}_{\mathrm{s} 1} \times \mathrm{W}_{\mathrm{s} 2} \mathrm{x} \cos \theta}(\mathrm{N})
$$

Dimana :

$\mathrm{W}_{\mathrm{s} 1}=$ Beban geser utama baut secara vertikal $(\mathrm{N})$

$\mathrm{W}_{\mathrm{s} 2}=$ Beban geser kedua baut

$\Theta \quad=$ Sudut arah gaya pada tiaptiap baut $\left(^{\circ}\right)$

4. Tegangan kerja $(\tau)$.

$$
\begin{aligned}
\tau & =\frac{\mathrm{F}}{\mathrm{A}}\left(\frac{\mathrm{N}}{\mathrm{mm}^{2}}\right) \\
& =\frac{\mathrm{F}}{\frac{\pi}{4} \cdot \mathrm{d}^{2}} \mathrm{~N} / \mathrm{mm}^{2}
\end{aligned}
$$

Dimana :

$\mathrm{F} \quad=$ Gaya pada tiap-tiap baut (N)

A $=$ Luas penampang baut $\left(\mathrm{m}^{2}\right)$

$\mathrm{d}=$ Diameter baut $(\mathrm{mm})$

5. Tegangan yang di izinkan $\left(\tau_{\mathrm{i}}\right)$.

$$
\tau_{\mathrm{i}}=\frac{\sigma_{\mathrm{B}}}{\left(\mathrm{sf}_{1} \times \mathrm{sf}_{2}\right)}\left(\mathrm{N} / \mathrm{mm}^{2}\right)
$$

(Sularso, 1985)

Dimana:

$\tau_{\mathrm{i}} \quad=$ Tegangan yang diizinkan $\left(\mathrm{N} / \mathrm{mm}^{2}\right)$ 
$\mathrm{Sf}_{1} \quad=$ Faktor keamanan satu 6

( umum )

$\mathrm{Sf}_{2} \quad=$ Faktor keamanan dua 1

( umum )

\section{Aluminium alloy.}

Aluminiumadalahlogamyang

memilikikekuatanyangrelatifrendahdan

lunak.Aluminiummerupakanlogam

yangringandanmemilikiketahanan

korosiyangbaik, hantaran listrikyangbaik dan sifat-sifat lainnya.

Aluminium paduan merupakan material berbasis aluminium kemudian ditambah dengan elemen paduan.

\section{Uji komposisi kimia.}

Uji komposisi merupakan pengujian yang diperuntukan untuk mengetahui seberapa besar jumlah kandungan yang terdapat pada suatu logam ferro maupun non ferro dengan menggunakan mesin yang disebut spectrometer, uji komposisi biasa dilakukan pada saat memulai suatu penelitian dari suatu benda uji, pada penelitian lengan rcws bahan yang digunakan ialah alumunium alloy, pada dasarnya memiliki kandungan unsur-unsur yang berbeda didalamnya, untuk pelaksanaannya menggunakan spectrometer jenis $x$-ray fluorosence $(X R F)$.

\section{Uji Kekerasan.}

Kekerasan adalah suatu sifat mekanik dari suatu material, kekerasan suatu material perlu diketahui terlebih pada penggunaan material yang mengalami pergesekan dan deformasi plastis.

\section{Pada penelitian lengan RCWS uji} kekerasan dilakukan menggunakan metode rockwell karena metode ini mempunyai sifat yaitu sederhana, cepat, lebih sedikit koreksi hasil yang terjadi dan mengurangi kerusakan benda uji karena hanya sedikit penekanan yang diperlukan, pengujian dilakukan dengan metode Rockwell B yang mana beban pendahulu(minor) sebesar $10 \mathrm{~kg}$ dan beban utama(mayor) sebesar $100 \mathrm{~kg}$ dengan waktu penetrasi selama 5 detik, indentor yang digunakan ialah 1/16" ball

\begin{tabular}{|c|c|lrl|}
\hline No & $\begin{array}{c}\text { Standart } \\
\text { AA }\end{array}$ & \multicolumn{3}{|c|}{ Keterangan } \\
\hline 1 & 1001 & $\begin{array}{l}\text { Al murni } 99,5 \% \\
\text { diatasnya }\end{array}$ & atau \\
\hline 2 & 1100 & $\begin{array}{l}\text { Al murni 99,0 \% } \\
\text { diatasnya }\end{array}$ \\
\hline 3 & $2 \times x x$ & $\begin{array}{l}\text { Cu merupakan unsur paduan } \\
\text { utama }\end{array}$ \\
\hline 4 & $3 \times x x$ & $\begin{array}{l}\text { Mn merupakan unsur paduan } \\
\text { utama }\end{array}$ \\
\hline 5 & $4 \times x x$ & $\begin{array}{l}\text { Si merupakan unsur paduan } \\
\text { utama }\end{array}$ \\
\hline 6 & $5 \times x x$ & $\begin{array}{l}\text { Mg merupakan unsur paduan } \\
\text { utama }\end{array}$ \\
\hline 7 & $6 x x x$ & $\begin{array}{l}\text { Mg2Si merupakan unsur } \\
\text { paduan utama }\end{array}$ \\
\hline 8 & $7 x x x$ & $\begin{array}{l}\text { Zn merupakan unsur paduan } \\
\text { utama }\end{array}$ \\
\hline
\end{tabular}

\section{Uji impak.}

Untuk menentukan sifat perpatahan suatu logam, keuletan maupun kegetasannya, 
dapat dilakukan suatu pengujian yang dinamakan dengan uji impak.

MetodeCharpy,sampel uji memiliki dimensi ukuran yaitu 10x10x55 mm. Dengan posisi takik (notch) berada di tengah, kedalaman takik $2 \mathrm{~mm}$ dari permukaan benda uji, dan sudut takik 45 derajat. Bentuk takik berupa huruf $\mathrm{U}, \mathrm{V}$, key hole (seperti lubang kecil).

1. Energi gesekan tanpa spesimen uji. $\mathrm{E}_{\mathrm{f}}=\mathrm{m}$. g. R $\left(\cos \beta_{\mathrm{o}}-\cos \right.$ $\left.\alpha_{\mathrm{o}}\right) \ldots(11)$

(Sumber :Pengujian Logam,2017)

Dimana:

$\mathrm{E}_{\mathrm{f}}=$ Energi gesek tanpa spesimen.

$\mathrm{m}=$ Massa.

$\mathrm{g}=$ Gravitasi.

$\mathrm{R}=$ Radius.

2. Energi ideal untuk mematahkan spesimen

$E_{f}=m \cdot g \cdot R\left(\cos \beta_{o}-\cos \alpha_{o}\right) \ldots$.

(Sumber : Pengujian Logam,2017)

Dimana:

Ef $=$ Energi untuk patahkan spesimen.

3. Energi aktual untuk patahkan specimen uji.

$\mathrm{E}_{\mathrm{ak}} \quad=\mathrm{E}_{\mathrm{a}}-\mathrm{F}_{\mathrm{f}}$

(Sumber : Pengujian Logam,2017)

Dimama

$\mathrm{E}_{\mathrm{ak}}=$ Energi untuk patahkan material dengan beban.

4. Harga impak.
$\mathrm{H}_{1} \quad=\frac{\text { Eak }}{\mathrm{h} \times \mathrm{l}}\left(\right.$ joule $\left./ \mathrm{mm}^{2}\right)$

(Sumber : Pengujian Logam,2017)

Dimana:

$\mathrm{H}_{1} \quad$ = Harga impak.

\section{Uji Tarik Bahan Lengan RCWS.}

Pengujian ini merupakan proses pengujian yang biasa dilakukan karena pengujian tarik dapat menunjukkan perilaku bahan selama proses pembebanan.

Tegangan diperoleh dengan membagi gaya tarik dengan luasan penampang mulamula dari spesimen

$$
\sigma=\mathrm{F} / \mathrm{A}\left(\mathrm{kg}_{\mathrm{f}} / \mathrm{mm}^{2}\right)
$$

(Sumber : Surdia Tata, 2000, hal 8)

Dimana :

$$
\begin{array}{ll}
\mathrm{F} & =\text { Gaya aksial }\left(\mathrm{kg}_{\mathrm{f}}\right) \\
\mathrm{A} & =\text { Luas penampang }\left(\mathrm{mm}^{2}\right)
\end{array}
$$

Regangan adalah perbandingan antara pertambahan panjang $(\Delta \mathrm{L})$ terhadap panjang mula-mula (L),

$$
\varepsilon=\Delta \mathrm{L} / \mathrm{L}_{\mathrm{O}}
$$

(Sumber : Surdia Tata, 2000, hal 8)

Dimana :

$\Delta \mathrm{L} \quad=$ perubahan panjang $(\mathrm{mm})$

$\mathrm{L} \quad=$ panjang awal $(\mathrm{mm})$ 
Alat

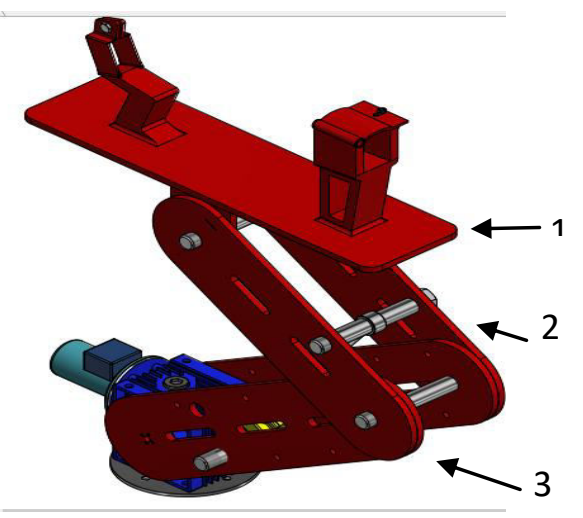

Keterangan :

1. Penyangga

senjata.

\section{Lengan 1.}

3. Lengan 2.

Diagram Alir.

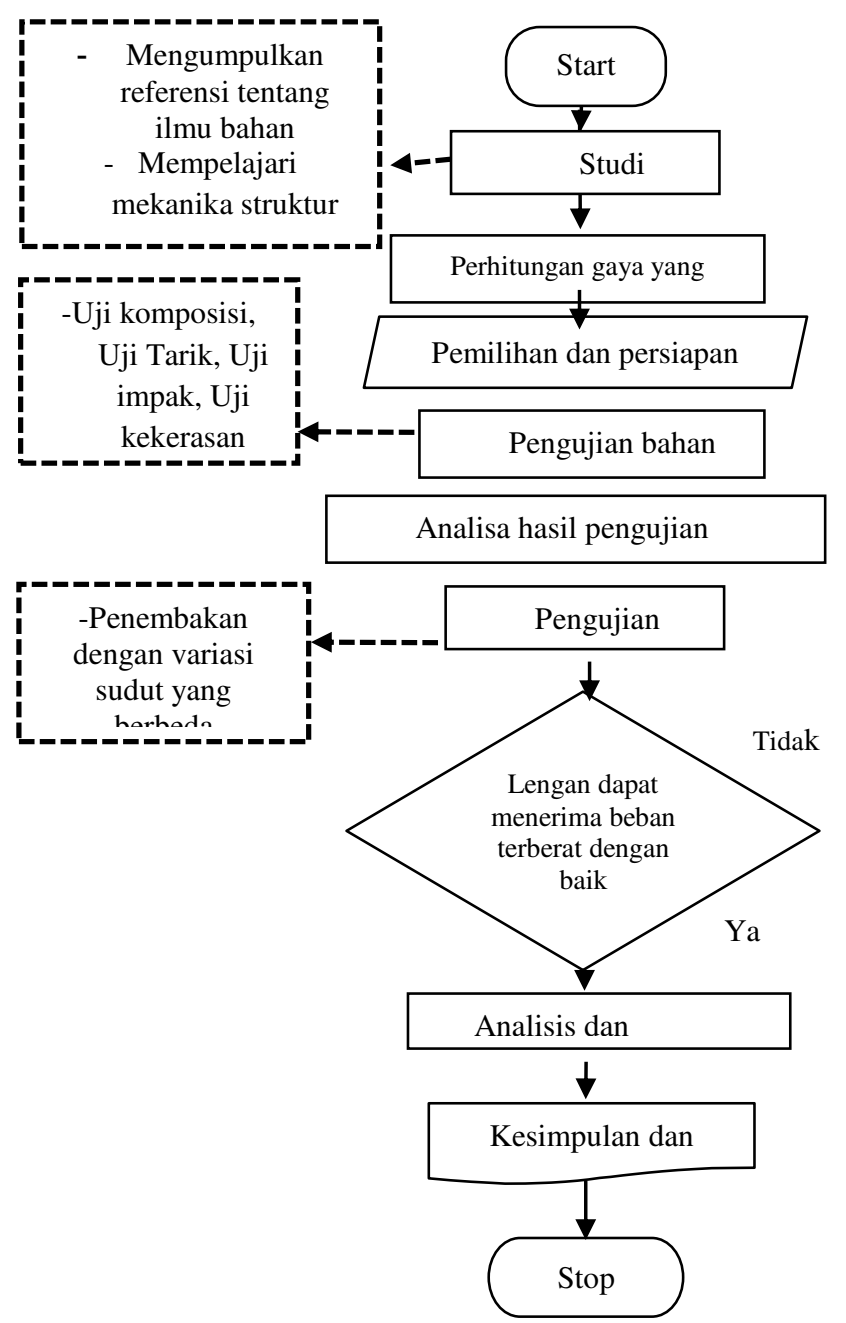

\section{Variabel Penelitian.}

Variabel bebas adalah variabel yang digunakan sebagai data perancangan, diantaranya sebagai berikut :

1. Beban lengan.

2. Bahan lengan.

3. Sudut penembakan.

Variabel Terikat adalah Variabeł yang diperoleh dari hasil analisa perhitungan variabel bebasnya. Dalam Rancang b̧angun ini variabel terikatnya adalah gaya pada lengan.

\section{Hasil Data Lengan RCWS.}

Berat total beban lengan 1 .

Berat senjata $\left(\mathrm{w}_{1}\right) \quad=48,02 \mathrm{~N}$

Berat dudukan senjata $\left(\mathrm{w}_{2}\right)=39,24 \mathrm{~N}$

Recoil penembakan $\left(\mathrm{w}_{3}\right) \quad=46,2266$

$\mathrm{N}$

Beban total lengan $1\left(\mathrm{w}_{\mathrm{t} 1}\right) \quad=133,45 \mathrm{~N}$

Tabel 4.1. Nilai Gaya Pada Lengan 1.

\begin{tabular}{|c|c|c|c|}
\hline No & $\alpha$ & $\operatorname{COS} \alpha$ & $\mathrm{F}(\mathrm{N})$ \\
\hline 1 & $60^{\circ}$ & 0,5 & 66,725 \\
\hline 2 & $70^{\circ}$ & 0,342 & 45,642 \\
\hline 3 & $80^{\circ}$ & 0,173 & 23,173 \\
\hline 4 & $90^{\circ}$ & 0 & 0 \\
\hline 5 & $100^{\circ}$ & $-0,173$ & $-23,173$ \\
\hline 6 & $110^{\circ}$ & $-0,342$ & $-45,642$ \\
\hline 7 & $120^{\circ}$ & $-0,5$ & $-66,725$ \\
\hline
\end{tabular}

Beban yang diterima lengan 2.

Total gaya pada lengan $1=84,633 \mathrm{~N}$

Berat lengan $1=27,46 \quad \mathrm{~N}$

Berat penggerak lengan $=19,62 \mathrm{~N}$ 
Beban total lengan $2=180,487 \mathrm{~N}$

Tabel.4.2. Nilai Gaya Pada Lengan 2.

\begin{tabular}{|l|l|l|l|}
\hline NO & \multicolumn{1}{|c|}{$\alpha$} & \multicolumn{1}{|c|}{$\cos \alpha$} & \multicolumn{1}{|c|}{$F(N)$} \\
\hline 1 & $20^{\circ}$ & 0,939 & 169,602 \\
\hline 2 & $30^{\circ}$ & 0,866 & 156,306 \\
\hline 3 & $40^{\circ}$ & 0,766 & 138,261 \\
\hline 4 & $50^{\circ}$ & 0,642 & 116,015 \\
\hline 5 & $60^{\circ}$ & 0,5 & 90,2435 \\
\hline 6 & $70^{\circ}$ & 0,342 & 61,73 \\
\hline 7 & $80^{\circ}$ & 0,173 & 31,34 \\
\hline 8 & $90^{\circ}$ & 0 & 0 \\
\hline
\end{tabular}

Reaksi gaya yang tejadi pada setiap lengan.

1.Reaksi gaya pada lengan 1 .

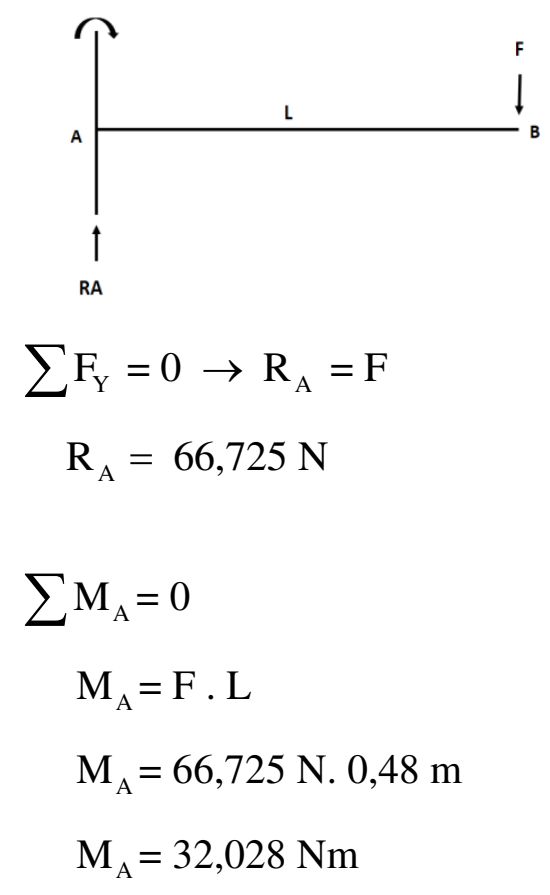

2. Reaksi gaya yang terjadi pada lengan 2 .

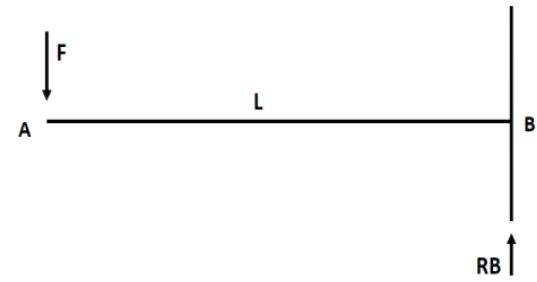

$$
\begin{aligned}
\sum \mathrm{F}_{\mathrm{Y}} & =0 \rightarrow \mathrm{R}_{\mathrm{B}}=\mathrm{F} \\
\mathrm{R}_{\mathrm{B}} & =169,602 \mathrm{~N} \\
\sum \mathrm{M}_{\mathrm{B}} & =0 \\
\mathrm{M}_{\mathrm{B}} & =\mathrm{F} \cdot \mathrm{L} \\
\mathrm{M}_{\mathrm{B}} & =169,602 \mathrm{~N} \cdot 0,59 \mathrm{~m} \\
\mathrm{M}_{\mathrm{B}} & =100,065 \mathrm{Nm}
\end{aligned}
$$

\section{Analisa Baut Pada Lengan RCWS Robot Tempur Kota.}

1. Gaya total pada lengan $(\mathrm{w})=180,487 \mathrm{~N}$

2. Jarak titik berat dengan pusat poros

$$
\begin{aligned}
& =29,5 \mathrm{~cm} \\
\text { 3. Diameter baut } & =7,3 \mathrm{~mm}
\end{aligned}
$$

Diketahui data seperti diatas maka dapat diketahui kekuatan baut yang ada pada lengan $R C W S$.

a. Momen puntir pada baut lengan RCWS.

$$
\begin{aligned}
\mathrm{M} & =\mathrm{W}_{\text {total }} \times \mathrm{e}(\mathrm{Nmm}) \\
& =180,487 \mathrm{~N} \times 295 \mathrm{~mm} \\
& =53243,665 \mathrm{Nmm}
\end{aligned}
$$


b. Beban yang terjadi pada baut(Ws)

$$
\begin{aligned}
\mathrm{W}_{\mathrm{s}} & =\frac{\mathrm{W}_{\text {total }}}{\mathrm{n}}(\mathrm{N}) \\
& =\frac{180,487 \mathrm{~N}}{4} \\
& =45,122 \mathrm{~N}
\end{aligned}
$$

c. Gaya geser maksimal pada baut (F).

$$
\begin{aligned}
\mathrm{F} & =\sqrt{\left(\mathrm{W}_{\mathrm{S}}\right)^{2}+2 \mathrm{~W}_{\mathrm{S}} \times \cos 20^{\circ}}(\mathrm{N}) \\
& =\sqrt{(45,122)^{2}+2.45,122 \times \cos 20^{\circ}} \\
& =46,052 \mathrm{~N}
\end{aligned}
$$

d. Tegangan kerja pada baut $(\tau)$.

$$
\begin{aligned}
\tau & =\frac{\mathrm{F}}{\frac{\pi}{4} \mathrm{~d}^{2}}\left(\frac{\mathrm{N}}{\mathrm{mm}^{2}}\right) \\
& =\frac{46,052 \mathrm{~N}}{\frac{3,14}{4} \cdot(10 \mathrm{~mm})^{2}} \\
& =0,587 \frac{\mathrm{N}}{\mathrm{mm}^{2}}
\end{aligned}
$$

e. Tegangan yang diizinkan $\left(\tau_{\mathrm{i}}\right)$.

$$
\begin{aligned}
\tau_{\mathrm{i}} & =\frac{\sigma_{\mathrm{B}}}{\left(\mathrm{sf}_{1} \times \mathrm{sf}_{2}\right)}\left(\frac{\mathrm{N}}{\mathrm{mm}^{2}}\right) \\
& =\frac{60 \mathrm{~N} / \mathrm{mm}^{2}}{(6 \times 1)} \\
& =10 \mathrm{~N} / \mathrm{mm}^{2}
\end{aligned}
$$

Tegangan yang diizinkan ialah 10

$\mathrm{N} / \mathrm{mm}^{2}$ lebih besar dari pada tegangan

kerja pada baut $0,587 \mathrm{~N} / \mathrm{mm}^{2}$ sehingga baut mampu menerima tegangan yang

terjadi.

Pengujian Komposisi Bahan.

\begin{tabular}{|c|c|c|}
\hline NO & Unsur & \% \\
\hline $\mathbf{1}$ & $\mathrm{Al}$ & 94,978 \\
\hline $\mathbf{2}$ & $\mathrm{Cr}$ & 0,46 \\
\hline $\mathbf{3}$ & $\mathrm{Cu}$ & 0,84 \\
\hline $\mathbf{4}$ & $\mathrm{Fe}$ & 0,207 \\
\hline $\mathbf{5}$ & $\mathrm{Mn}$ & 0,360 \\
\hline $\mathbf{6}$ & $\mathrm{Ni}$ & 0,001 \\
\hline $\mathbf{7}$ & $\mathrm{Si}$ & 0,105 \\
\hline $\mathbf{8}$ & $\mathrm{Ti}$ & 0,011 \\
\hline $\mathbf{9}$ & $\mathrm{Zn}$ & 0,071 \\
\hline $\mathbf{1 0}$ & $\mathrm{Mg}$ & 4,296 \\
\hline
\end{tabular}

Pada tabel 4.3 memperlihatkan bahwa kandungan aluminuium (Al) sebesar $94,978 \%$, unsur alloy utama pada paduan ini ialah magnesium $(\mathrm{Mg})$ yaitu sebesar 4,297\%. Berdasarkan ASM Handbook vol 02 non ferrous tabel 2 tentang alumunium paduan maka dapat diketahui bahwa bahan yang digunakan ialah aluminium alloy seri 5083 sesuai standar AA (Alumunium Association of America). Sifat dari alumunium 5083 itu sendiri ialah mempunyai keuletan yang baik, mudah dibentuk dan mepunyai ketahanan korosi yang tinggi. 


\section{Pengujian Kekerasan.}

Tabel.4.4. Tabel Pengujian Kekerasan

Rockwell

\begin{tabular}{|c|c|c|}
\hline $\begin{array}{c}\text { No } \\
\text { Pengujian }\end{array}$ & $\begin{array}{c}\text { Harga } \\
\text { Kekerasan } \\
\mathrm{HR}_{\mathrm{B}}\end{array}$ & $\begin{array}{c}\text { Rata-rata } \\
\text { Kekerasan }\end{array}$ \\
\hline 1 & 21,5 & \\
\hline 2 & 23 & \\
\hline 3 & 22,5 & 23 \\
\hline 4 & 23 & \\
\hline 5 & 24 & \\
\hline 6 & 24 & \\
\hline
\end{tabular}

Jadi untuk harga kekerasan dari

bahan aluminium seri 5083 ialah $23 \mathrm{HR}_{\mathrm{B}}$.

\section{Pengujian Kekuatan Impack.}

Diketahui data sebagi berikut :

Massa pendulum

$$
=26,2 \mathrm{~kg}
$$$$
\text { Gravitasi yang digunakan= }
$$$$
9,81 \mathrm{~m} / \text { detik }^{2}
$$$$
\text { Radius lengan Pendulum } \quad=0,75 \mathrm{~m}
$$

Tabel.5. Tabel Data Sepesimen Uji.

\begin{tabular}{|l|c|c|c|c|c|c|}
\hline $\mathbf{N o}$ & $\begin{array}{c}\mathbf{p} \\
(\mathbf{m m})\end{array}$ & $\begin{array}{c}\mathbf{l} \\
(\mathbf{m m})\end{array}$ & $\begin{array}{c}\mathbf{t} \\
(\mathbf{m m})\end{array}$ & $\begin{array}{c}\mathbf{h} \\
(\mathbf{m m})\end{array}$ & $\begin{array}{c}\mathbf{T} \\
\left(\mathbf{C}^{\mathbf{0}}\right)\end{array}$ & $\begin{array}{c}\mathbf{A} \\
\left(\mathbf{m m}^{\mathbf{2}}\right)\end{array}$ \\
\hline $\mathbf{1}$ & 58 & 10 & 10,25 & 8 & 25 & 80 \\
\hline $\mathbf{2}$ & 58,5 & 10,5 & 10,25 & 8 & 25 & 84 \\
\hline $\mathbf{3}$ & 58 & 10,35 & 10,25 & 8 & 25 & 82,8 \\
\hline $\mathbf{4}$ & 55 & 10 & 10 & 7 & 25 & 70 \\
\hline $\mathbf{5}$ & 55 & 10 & 10 & 7 & 25 & 70 \\
\hline $\mathbf{6}$ & 55 & 10 & 10 & 7 & 25 & 70 \\
\hline
\end{tabular}

\begin{tabular}{|l|l|l|l|l|l|l|}
\hline $\mathbf{7}$ & 55 & 10 & 10 & 7 & 25 & 70 \\
\hline
\end{tabular}

Tabel.6. Tabel Sudut Simpangan.

\begin{tabular}{|c|c|c|c|c|}
\hline $\begin{array}{c}\text { No } \\
\text { Beban }\end{array}$ & \multicolumn{2}{|c|}{$\begin{array}{c}\text { Sudut } \\
\text { Simpangan } \\
\text { Dengan Beban }\end{array}$} & \multicolumn{2}{c|}{$\begin{array}{c}\text { Sudut Simpangan } \\
\text { Tanpa Beban }\end{array}$} \\
\cline { 2 - 3 } & Sudut & Sudut & Sudut $\boldsymbol{\alpha}$ & Sudut $\beta$ \\
$\boldsymbol{\alpha}$ & $\boldsymbol{\beta}$ & & \\
\hline 1 & 100 & 65 & & \\
\hline 2 & 100 & 55 & & \multirow{2}{*}{100} \\
\hline 3 & 100 & 68 & \multirow{2}{*}{92} \\
\hline 4 & 100 & 79 & & \\
\hline 5 & 100 & 73 & & \\
\hline 6 & 100 & 70 & & \\
\hline 7 & 100 & 75 & & \\
\hline
\end{tabular}

Perhitugan Energi.

1. Energi titik A, yaitu nilai energi sebelum pendulum jatuh.

$$
\begin{array}{ll}
\mathrm{E}_{\mathrm{A}} & =\text { m.g.R. }(1-\operatorname{Cos} \alpha) \\
\mathrm{E}_{\mathrm{A}} & =26,2 \mathrm{~kg} \cdot 9,81 \mathrm{~m} / \mathrm{detik}^{2} . \\
& 0,75 \mathrm{~m}\left(1-\cos 100^{\circ}\right) \\
\mathrm{E}_{\mathrm{A}} & =226,24 \text { Joule. }
\end{array}
$$

2. Energi titik $B$, yaitu nilai energi setelah pendulum jatuh.

$\mathrm{E}_{\mathrm{B} 1} \quad=$ m.g.R.(1-Cos $\left.\beta\right)$

$\mathrm{E}_{\mathrm{B} 1}=26,2 \mathrm{~kg} \cdot 9,81 \mathrm{~m} / \mathrm{detik}^{2}$.

$0,75 \mathrm{~m}\left(1-\cos 65^{\circ}\right)$

$\mathrm{E}_{\mathrm{B} 1}=111,3$ Joule

3. Energi yang diperlukan untuk mematahkan spesimen uji.

$$
\begin{array}{cl}
\mathrm{E}_{\mathrm{A}}-\mathrm{E}_{\mathrm{B} 1} & =226,244 \text { joule - } \\
& 111,3 \text { Joule }
\end{array}
$$




$$
=114,944 \text { Joule }
$$

Tabel.7. Nilai Energi Untuk Patahkan Spesimen.

Perhitungan Harga Impak(HI) Atau Impact Strenght(IS).

1. Energi gesekan (friction) (Ef).

$$
\begin{aligned}
\mathrm{E}_{\mathrm{f}} & =\mathrm{m} \cdot \mathrm{g} \cdot \mathrm{R} \cdot(\operatorname{Cos} \beta-\operatorname{Cos} \alpha) \\
\mathrm{E}_{\mathrm{f}}= & 26,2 \mathrm{~kg} \cdot 9,81 \mathrm{~m} / \mathrm{detik}^{2} . \\
& 0,75 \mathrm{~m}\left(\operatorname{Cos} 92^{0}-\operatorname{Cos} 100^{\circ}\right) \\
\mathrm{E}_{\mathrm{f}}= & 192,77 \cdot(0,139) \\
\mathrm{E}_{\mathrm{f}} & =26,75 \text { Joule }
\end{aligned}
$$

2. Energi ideal $\left(\mathrm{E}_{\mathrm{id}}\right)$.

$$
\begin{aligned}
\mathrm{E}_{\mathrm{id} 1} & =\text { m.g.R. }\left(\operatorname{Cos} \beta_{1}-\operatorname{Cos} \alpha_{1}\right) \\
\mathrm{E}_{\mathrm{id} 1} & =26,2 \mathrm{~kg} \cdot 9,81 \mathrm{~m} / \mathrm{detik}^{2} . \\
& 0,75 \mathrm{~m}\left(\operatorname{Cos} 65^{\circ}-\operatorname{Cos} 100^{\circ}\right) \\
\mathrm{E}_{\mathrm{id} 1} & =192,77 \cdot(0,596) \\
\mathrm{E}_{\mathrm{id} 1} & =114,94 \text { Joule }
\end{aligned}
$$

\begin{tabular}{|c|c|c|c|c|c|c|}
\hline & $\begin{array}{c}\text { NO } \\
\text { BEBAN }\end{array}$ & \multicolumn{2}{|c|}{$\mathbf{E}_{\mathbf{A}}$} & $\mathbf{E}_{\mathrm{B}}$ & \multicolumn{2}{|c|}{$\begin{array}{c}\text { ENERGI } \\
\text { DIPERLUKAN } \\
\text { UNTUK } \\
\text { PATAHKAN } \\
\text { SPESIMEN } \\
\end{array}$} \\
\hline & 1 & \multirow{7}{*}{\multicolumn{2}{|c|}{$\begin{array}{c}226,24 \\
\text { Joule }\end{array}$}} & $\begin{array}{l}11 \\
\text { Jol } \\
\end{array}$ & \multicolumn{2}{|c|}{114,944 joule } \\
\hline & 2 & & & $\begin{array}{c}82 \\
\text { Jol }\end{array}$ & \multicolumn{2}{|c|}{144,042 joule } \\
\hline & 3 & & & $\begin{array}{r}120 \\
\text { Jol } \\
\end{array}$ & \multicolumn{2}{|c|}{105,667 joule } \\
\hline & 4 & & & $\begin{array}{r}155 \\
\text { Jol } \\
\end{array}$ & \multicolumn{2}{|c|}{70,255 joule } \\
\hline & 5 & & & $\begin{array}{r}136 \\
\text { Jol }\end{array}$ & \multicolumn{2}{|c|}{89,833 joule } \\
\hline & 6 & & & $\begin{array}{r}126 \\
\text { Jol } \\
\end{array}$ & \multicolumn{2}{|c|}{99,403 joule } \\
\hline & 7 & & & 142 & \multicolumn{2}{|c|}{83,365 joule } \\
\hline No & & & & Jol & Energi & Harga \\
\hline Beban & $\begin{array}{r}E \\
\text { (Jou }\end{array}$ & & 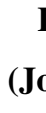 & & $\begin{array}{l}\text { Aktual } \\
\text { (Joule) }\end{array}$ & $\begin{array}{c}\text { Impak } \\
(\text { joule/mm²) }\end{array}$ \\
\hline 1 & \multirow{7}{*}{\multicolumn{2}{|c|}{26,75}} & & ,94 & 88,19 & 1,102 \\
\hline 2 & & & &, 04 & 117,289 & 1,396 \\
\hline 3 & & & 105 & 685 & 78,935 & 0,956 \\
\hline 4 & & & & 255 & 43,509 & 0,621 \\
\hline 5 & & & & 833 & 63,086 & 0,901 \\
\hline 6 & & & & & 72,657 & 1,037 \\
\hline 7 & & & & 365 & 56,619 & 0,808 \\
\hline
\end{tabular}

3. Energi aktual $\left(\mathrm{E}_{\mathrm{ak}}\right)$.

$$
\begin{aligned}
& E_{\mathrm{ak} 1}=E_{\text {id } 1}-E_{f} \\
& E_{a k 1}=114,94 \text { joule }-26,75 \text { joule } \\
& E_{a k_{1}}=88,19 \text { Joule }
\end{aligned}
$$

4. Harga Impak (HI).

$$
\begin{aligned}
& \mathrm{HI}_{1}=\frac{\text { Eak } 1}{A} \\
& \mathrm{HI}_{1}=\frac{88,19}{80} \\
& \mathrm{HI}_{1}=1,102 \text { Joule } / \mathrm{mm}^{2}
\end{aligned}
$$

\section{Tabel.4.8. Nilai Harga Impak Pada} Beban

Sifat ketangguhan pada material alumunium 5083, diperoleh harga impak terbesar ialah 1,396 joule $/ \mathrm{mm}^{2}$, yaitu setiap 1 $\mathrm{mm}^{2}$ mampu menahan energi sebesar 1,396 joule.

\section{Pengujian Tarik Bahan Lengan.}

$$
\text { Pengujian dilakukan untuk }
$$
mengetahui nilai dari tegangan tarik maksimal dari bahan alumunium 5083 dan mengetahui titik putus dari bahan tersebut. 
Tabel.4.9. Hasil Pengujian Tarik.

\begin{tabular}{|c|c|c|c|c|c|c|c|c|c|}
\hline No & $\begin{array}{c}\mathbf{L o} \\
(\mathbf{m m})\end{array}$ & $\begin{array}{c}\text { Bo } \\
(\mathbf{m m})\end{array}$ & $\begin{array}{c}\text { To } \\
(\mathbf{m m})\end{array}$ & $\begin{array}{c}\mathbf{L f} \\
(\mathbf{m m})\end{array}$ & $\begin{array}{c}\mathbf{B f} \\
(\mathbf{m m})\end{array}$ & $\begin{array}{c}\mathbf{T f} \\
(\mathbf{m m})\end{array}$ & $\begin{array}{c}\mathbf{A o} \\
\left(\mathbf{m m}^{2}\right)\end{array}$ & $\begin{array}{c}\mathbf{A f} \\
\left(\mathbf{m m}^{2}\right)\end{array}$ & $\begin{array}{l}\mathbf{P m a x} \\
(\mathbf{k g f})\end{array}$ \\
\hline $\mathbf{1}$ & 58,6 & 13 & 6 & 71 & 10 & 2,1 & 78 & 21 & 815,5 \\
\hline $\mathbf{2}$ & 54 & 13 & 5,8 & 65,7 & 10 & 2,1 & 75,4 & 21 & 1000 \\
\hline $\mathbf{3}$ & 54,5 & 11,7 & 5,8 & 65,8 & 8,6 & 2,5 & 67,86 & 21,5 & 937,5 \\
\hline $\mathbf{4}$ & 56 & 12.7 & 5,9 & 69,5 & 8,4 & 2,4 & 74,93 & 20,16 & 972,5 \\
\hline
\end{tabular}

Tegangan maksimal.

$$
\begin{aligned}
\sigma & =\frac{F}{A} \\
& =\frac{815,5 \mathrm{kgf}}{78 \mathrm{~mm}^{2}} \\
& =10,45 \mathrm{kgf} / \mathrm{mm}^{2}
\end{aligned}
$$

Tabel.4.10. Nilai Tegangan Maksimal.

\begin{tabular}{|c|c|c|c|}
\hline $\begin{array}{c}\text { No } \\
\text { Spesimen }\end{array}$ & $\begin{array}{c}\mathbf{F} \\
(\mathbf{k g f})\end{array}$ & $\begin{array}{c}\mathbf{A} \\
\left(\mathbf{m m}^{\mathbf{2}}\right)\end{array}$ & $\begin{array}{c}\text { Tegangan } \\
\text { Maksimal } \\
\left(\mathbf{k g f} / \mathbf{m m}^{\mathbf{2}}\right)\end{array}$ \\
\hline $\mathbf{1}$ & 815,5 & 78 & 10,45 \\
\hline $\mathbf{2}$ & 1000 & 75,4 & 13,263 \\
\hline $\mathbf{3}$ & 937,5 & 67,86 & 13,815 \\
\hline $\mathbf{4}$ & 972,5 & 74,93 & 12,979 \\
\hline
\end{tabular}

\begin{tabular}{|c|c|c|c|}
\hline $\begin{array}{c}\text { No } \\
\text { Spesimen }\end{array}$ & $\begin{array}{c}\text { Panjang } \\
\text { Gaya } \\
\text { Maksimal }\end{array}$ & $\begin{array}{c}\text { Panjang } \\
\text { Tekanan } \\
\text { Putus }\end{array}$ & $\begin{array}{c}\text { Panjang } \\
\text { Tekanan } \\
\text { Luluh }\end{array}$ \\
\hline $\mathbf{1}$ & $36 \mathrm{~mm}$ & $27 \mathrm{~mm}$ & $29 \mathrm{~mm}$ \\
\hline $\mathbf{2}$ & $47 \mathrm{~mm}$ & $39 \mathrm{~mm}$ & $42 \mathrm{~mm}$ \\
\hline $\mathbf{3}$ & $46 \mathrm{~mm}$ & $38 \mathrm{~mm}$ & $39 \mathrm{~mm}$ \\
\hline $\mathbf{4}$ & $48 \mathrm{~mm}$ & $40 \mathrm{~mm}$ & $43 \mathrm{~mm}$ \\
\hline
\end{tabular}

Setelah diketahui nilai dari tegangan maksimal dan luas penampang dari suatu spesimen yaitu pada tabel 4.10, akan diketahui nilai setiap mm dari gambar grafik uji tarik,

Tabel.4.12. Nilai Tegangan Titik Putus.

\section{Titik putus dan titik luluh.}

Untuk mengetahui pada titik berapa bahan lengan akan putus, gaya yang terjadi pada saat lengan putus, dan mengetahui berapa nilai titik luluh,

Tabel.4.11. Nilai Grafik Kertas Uji pada Kertas.

\begin{tabular}{|c|c|c|}
\hline $\begin{array}{c}\text { No } \\
\text { Spesimen }\end{array}$ & $\begin{array}{c}\text { Tegangan } \\
\text { Titik Putus }\end{array}$ & $\begin{array}{c}\text { Tegangan Titik } \\
\text { Luluh }\end{array}$ \\
\hline 1 & $7,837 \mathrm{kgf} / \mathrm{mm}^{2}$ & $8,41 \mathrm{kgf} / \mathrm{mm}^{2}$ \\
\hline 2 & $11 \mathrm{kgf} / \mathrm{mm}^{2}$ & $11,582 \mathrm{kgf} / \mathrm{mm}^{2}$ \\
\hline 3 & $11,41 \mathrm{kgf} / \mathrm{mm}^{2}$ & $11,712 \mathrm{kgf} / \mathrm{mm}^{2}$ \\
\hline 4 & $10,81 \mathrm{kgf} / \mathrm{mm}^{2}$ & $11,627 \mathrm{kgf} / \mathrm{mm}^{2}$ \\
\hline
\end{tabular}

Jadi tegangan maksimal dari bahan lengan RCWS yaitu alumunium 5083 ialah $13,815 \mathrm{kgf} / \mathrm{mm}^{2}$, dengan tegangan titik putus $11,41 \mathrm{kgf} / \mathrm{mm}^{2}$ dan tegangan luluh 11,712 $\mathrm{kgf} / \mathrm{mm}^{2}$ dan gaya maksimal 937,5 kgf, nilai 
tegangan maksimal lebih besar dibandingkan dengan nilai gaya maksimal yang diterima lengan $R C W S$ yaitu sebesar $0,02 \mathrm{kgf} / \mathrm{mm}$

\section{Uji Tembak}

\begin{tabular}{|l|l|l|l|}
\hline \multicolumn{1}{|l}{ No } & \multicolumn{1}{l}{$\begin{array}{l}\text { Sudut } \\
\text { Lengan 1 }\end{array}$} & \multicolumn{1}{l|}{$\begin{array}{l}\text { Sudut } \\
\text { Lengan 2 }\end{array}$} & \multicolumn{1}{l|}{$\begin{array}{l}\text { Hasil } \\
\text { Penembakan }\end{array}$} \\
\hline 1 & 70 & 20 & Mampu \\
\hline 2 & 80 & 40 & Mampu \\
\hline 3 & 90 & 60 & Mampu \\
\hline 4 & 110 & 80 & Mampu \\
\hline
\end{tabular}

\section{Kesimpulan}

Dari hasil analisis karakterisi bahan lengan RCWS pada robot tempur kota terhadap variasi sudut penembakan maka dapat diperoleh beberapa kesimpulan sebagai berikut :

a. Pada lengan 1 dengan berat total $133,45 \mathrm{~N}$ gaya terbesar yang terjadi yaitu pada saat lengan membentuk sudut $60^{\circ}$ dengan nilai $66,725 \mathrm{~N}$.

b. Pada lengan 2 dengan berat total $180,487 \mathrm{~N}$ gaya terbesar yang terjadi yaitu pada saat lengan membentuk sudut $20^{\circ}$ dengan nilai $169,602 \mathrm{~N}$.

c. Analisa pada baut tegangan yang diizinkan ialah $10 \mathrm{~N} / \mathrm{mm}^{2}$ lebih besar dari pada tegangan kerja pada baut $0,587 \mathrm{~N} / \mathrm{mm}^{2}$ sehingga baut mampu menerima tegangan yang terjadi.

d. Bahan lengan RCWS merupakan material alumunium paduan dengan seri 5083, mempunyai sifat keuletan yang baik, mudah dibentuk dan mepunyai ketahanan korosi yang tinggi dengan nilai kekerasan sebesar 23 HRB.

e. Ketangguhan pada material alumunium 5083, diperoleh harga impak terbesar ialah 1,396 Joule $/ \mathrm{mm}^{2}$, yaitu setiap $1 \mathrm{~mm}^{2}$ mampu menahan energi sebesar 1,396 joule.

f. Tegangan maksimal dari bahan lengan $R C W S$ yaitu alumunium 5083 ialah 13,815 $\mathrm{kgf} / \mathrm{mm}^{2}$, dengan tegangan titik putus $11,41 \mathrm{kgf} / \mathrm{mm}^{2}$, nilai tegangan maksimal lebih besar dibandingkan dengan nilai tegangan maksimal yang diterima lengan $R C W S y a i t u \quad 0,02 \mathrm{kgf} / \mathrm{mm}^{2}$.

g. Setelah dilaksanakan penembakan dengan berbagai sudut yang berbeda, lengan tetap mampu menhan beban yang terjadi.

\section{SIMPULAN}

Dari hasil analisis karakteristik bahan lengan RCWS pada robot tempur kota terhadap variasi sudut penembakan dan pengujian lengan secara dinamis maka dapat diperoleh 
beberapa saran agar dalampenelitian selanjutnya lebih baik dari penelitian sekarang :

a. Perlu dilakukan uji kelelahan agar kedepannya dapat diketahui lebih banyak data karakteristik dari bahan lengan.

b. Agar menghitung kekuatan komponen penggerak lengan 1.

c. Diharapkan lengan tersebut lebih dikembangkan dengan berbagaifungsi militer lainnya dan mampu untuk menopang senjata yang lebih besar dari SS2.

d. Agar menambahan pengatur otomatis sudut gerak elevasi pada lengan.

\section{DAFTAR PUSTAKA}

Handbook of Mechanics, Material, and Structures, 316

Irawan Purna Agustinus, 2007,Diktat Mekanika-Teknik-Statika Struktur,hal 17.

Khurmi, R.S. Gupta, J.K.2005. A Textbook for the students of Machine Design (S.I. Units). Ram-Nagar, New Delhi : Eurasia Publishing House (PVT.) LTD.

Panduan Bimbingan dan Praktikum Pengujian Logam. 2017. Malang. Universitas Merdeka Malang.
R.E.Smallman, R.J.Bishop. 1995, Metals and Materials, hal 331.

Sears dan Zemansky. 1982. Fisika untuk Universitas 1. Mekanika. Panas. Bunyi. Bandung : Binacipta.

Statika, TEDC Bandung, hal 3.

Sularso, Ir. 1987. Dasar Perencanaan dan pemilihan Elemen Mesin. Jakarta: Pradya Paramita.

Surdia Tata. 2000. Pengetahuan Bahan Teknik. hal 18 